\title{
The effect of intensification of shifting cultivation in Africa on stabilizing land-use and forest conservation
}

K. F. Wiersum (Department Forest Management, Agricultural University, P.O. Box 342, $6700 \mathrm{AH}$ Wageningen, Netherlands)

Received 23 January 1986; accepted 16 June 1986

\begin{abstract}
Intensification of shifting cultivation to permanent agriculture has been proposed as a means to stabilize land-use and to protect forest resources in tropical countries. Based on the results of four African case-studies it is shown that it cannot be expected that changes in cultivation practices in itself will have these results. Rather the new cultivation systems should be combined with measures to control possible negative effects in the socio-economic environment including changed attitudes towards land as a productive factor, and with measures to sustain the multifunctional characteristics of shifting cultivation.

Key words: agricultural intensification, farming systems, forest conservation, shifting cultivation, sustained land-use.
\end{abstract}

Introduction. Shifting cultivation is still one of the most widespread forms of land utilization in the humid tropics. At present several interrelated factors such as increase in population by indigenous growth and immigration, and rising demands for commercial exploitation and cultivation of land are causing an increased pressure on land and the predominance of various forms of deteriorated and exploitative forms of shifting cultivation. Shifting cultivation is therefore often blamed as one of the major reasons for the loss of valuable forest resources and land degradation. Consequently, in many discussions on the need for tropical forest resource conservation the need for stabilizing land-use through intensification of shifting cultivation is emphasized. As alternatives various cultivation systems have been proposed, such as permanent annual cultivation, perennial tree crop cultivation or various forms of agroforestry (FAO, 1984a, 1984b). Such intensification of agricultural cultivation has been introduced in many areas with shifting cultivation. The explicit aim of such projects was often to increase agricultural production rather than the conservation of forest resources. But by analysing the results of these endeavours, it is possible to assess to what extent an intensification of shifting cultivation to permanent agriculture does indeed contribute to stabilization of land-use and forest conservation.

Purpose and methodology. In order to assess the effect of the intensification of shifting cultivation on stabilization of land-use and on conservation of forest and tree resources, four case-studies were made of changes in shifting cultivation systems in regions of Ivory Coast, Madagascar, Sierra Leone and Tanzania. In each study the traditional land-use system was described as to natural and socio-economic envi- 


\section{K. F. WIERSUM}

ronment and to cultivation and production characteristics (Tiffen, 1984). Changes in the land-use system resulting either from indigenous adaptive strategies or outside interventions (UNESCO, 1978) were also described. Both traditional and alternative cultivation systems were analysed as to the following types of stability (modified after Harwood, 1979):

a) ecological stability meaning the resilient and resistant adaptation of cropping systems to perturbating factors such as extreme weather conditions, pests and diseases and soil degradation;

b) management resilience in the sense of a resilient adaptation of management techniques to both ecological conditions and variable management factors;

c) production sustainability resulting from the interaction between ecological and management factors;

d) economic reliability or the resilient adaptation to changes in economic conditions.

In addition the effect on forest and tree resources was taken into account.

The studies were primarily based on a review of published data, but in Ivory Coast and Madagascar additional field data were collected.

Results. The traditional indigenous shifting cultivation systems generally provided a sustained production of agricultural products for local use. In these systems ecological stability and production sustainability were preserved by various management practices, which provided for resilience against variable and adverse weather conditions, biotic perturbations and soil degradation and erosion. They also limited labour peaks with related labour shortages. Trees played an important role in such systems, not only as fallow crops regenerating physical and chemical soil properties and suppressing weeds, pests and diseases, but also by the production of basic needs such as various kinds of food, fuel and timber. Due to the extensive nature of these forms of shifting cultivation, forest resources were traditionally not much affected by these types of land-use.

However, this ecological stability and production sustainability has been broken down in the currently prevailing forms of deteriorated and exploitative shifting cultivation. These systems are characterized by the availability of less land per cultivator, lower fallow/cultivation ratios, and often also decreased crop and tree diversity. Under such conditions it has been tried to radically change agriculture through government interventions. The objective of these interventions has mostly been to stimulate permanent agricultural cultivation by the use of adapted improved crop cultivars, chemical fertilizers, pesticides and insecticides, increased soil tillage and terracing, etc. This high-input approach was mostly directed at the production of commercial goods, and consequently the bundle of innovations often included also new credit and marketing facilities. Both annual foodcrops such as rice or vegetables and perennial cash crops such as coffee, tea, cocoa and oilpalm as well as timber trees have been used in such development schemes. In many cases the young tree crop plantations were intercropped with foodcrops.

Although the new cropping practices are generally less stable ecologically than the traditional cropping practices, under favourable conditions they have proven to 
provide sustained yields in case that well-adapted management practices resilient to the ecological conditions are applied (cf. Ruthenberg, 1980). However, several socio-economic constraints limit the adoption of such high-input cultivation systems, e.g. the generally low returns to family labour (as opposed to increased returns from land), increased peak labour demands, lack of capital to obtain inputs including increased amounts of hired labour, and need for good marketing conditions. In several cases the new cultivation systems did not only show low resilience to the variable socio-economic environment, but also low economic reliability and increased risks.

On the other hand it can be observed that under certain favourable socio-economic conditions a spontaneous change from shifting cultivation to permanent agriculture may take place (cf. FAO, 1984b). For instance, in parts of West Africa an indigenous change from shifting cultivation to perennial cash crop cultivation has occurred. This change resulted from a well-established market for the low-bulk and non-perishable tree products, and from access to the needed inputs due to either increased off-farm employment providing cash for investment in agriculture, or due to the possibility for immigrant farmers to tap labour and capital from their native regions.

An important consequence of the development of the intensified cultivation systems is that they mostly bring about the incorporation of farming into a commercial system. This results in many changes in attitudes towards the production factors. For instance, many traditional communal arrangements in relation to the use of land and labour become privatized. In several cases the need for an expanding resource base needed for cash crop production has led to a process of competition for land. This may result in occupation of maximal amounts of land, which are only nominally managed to discourage claims of other land users. Under such conditions of land speculation and nominal management the change of shifting cultivation to permanent cultivation does not result in stabilization of land-use, but rather to a further intrusion of agricultural land into the forest.

A second reason why the development of intensified cultivation systems may not contribute to stabilization of land-use, results from the fact that its objective is normally directed at increased production of a specific commodity, and not at offering an alternative to the multiple-production characteristics of shifting cultivation. In several regions the new cultivation systems are therefore additional to shifting cultivation rather than a replacement. While in areas where shifting cultivation is actually replaced, pressure on forest resources may still ensue if insufficient trees providing products for local people are left in the agricultural fields. Or if food production through intercropping in tree crop plantations cannot be sustained at maturity of these plantations, which have a longer rotation period than the traditional fallow vegetation.

During recent years more efforts are directed at developing new cultivation systems, in which food production for local needs and tree growing are intimately integrated. This experimental approach results partly from the realization that proper management of the protective properties of trees may assist in developing low-input cultivation systems, which have a higher management resilience than the high- 
input systems. Furthermore, the development of these systems is also stimulated by the realization that both local food production and many tree products remain essential to most rural people. The development of such multi-functional cultivation systems holds more promise for contributing to the conservation of essential forest and tree resources than monofunctional cash-crop cultivation systems.

Conclusion. Intensification of shifting cultivation to permanent agriculture will not in itself result in stabilized land-use and diminished pressure on forest resources. It will only do so, if the intensification is combined with measures to control possible negative effects on the socio-economic environment including changed attitudes towards forest land, and if the multi-functional characteristics of shifting cultivation are maintained.

\section{References}

FAO, 1984a. Improved production systems as an alternative to shifting cultivation. FAO Soils Bulletin No 53. FAO, Rome, Italy, 201 pp.

FAO, 1984b. Changes in shifting cultivation in Africa. FAO Forestry Paper No 50. FAO Forestry Department, Rome, Italy, $59 \mathrm{pp}$.

Harwood, R. R., 1979. Small farm development. Understanding and improving farming systems in the humid tropics. Westview Press, Boulder, Colorado, $160 \mathrm{pp}$.

Ruthenberg, H. , 1980. Farming systems in the tropics, 3rd ed. Clarendon Press, Oxford, 424 pp.

Tiffen, M., 1984. Institutional aspects of shifting cultivation in Africa. Report, Human resources, institutions and agrarian reform division, FAO, Rome, Italy, $171 \mathrm{pp}$.

UNESCO, 1978. Management of natural resources in Africa: traditional strategies and modern decision making. MAB Technical Notes No 9. UNESCO, Paris, France, 81 pp.

This synopsis is based on a report by K. F. Wiersum entitled 'Forestry aspects of stabilizing shifting cultivation in Africa', Forestry Departments 'Hinkeloord', Agricultural University, Wageningen, 1985. 200 pp., 31 figs., 27 tables, 100 refs.

Available as paper copy (order R056P, $f 15$ including postage) or microfiches (or$\operatorname{der} R 056 M, f 22.50)$ at: NARD, clo Pudoc, P.O. Box 4, 6700 AA Wageningen, Netherlands (telex 45015 blhwg $\mathrm{hl}$ ).

SYNOPSIS

\section{Simulation of aphid damage in winter wheat}

H. J. W. van Roermund, J. J. R. Groot, W. A. H. Rossing and R. Rabbinge (Department of Theoretical Production Ecology, Agricultural University, P.O. Box 430, $6700 \mathrm{AK}$ Wageningen, Netherlands)

Received 24 April 1986; accepted 20 June 1986

Abstract. To study the effect of the English grain aphid, Sitobion avenae (F.), on dry matter accumulation in winter wheat grains, the influence of aphids on plant 